\title{
Specimen's Geometry Related Influences on Load-Bearing Capacity of Joining Aluminium and UHSS by Innovative Shear-Clinching
}

\author{
Réjane Hörhold ${ }^{1}$, Martin Müller ${ }^{2}$, Marion Merklein ${ }^{2}$ \& Gerson Meschut ${ }^{1}$ \\ ${ }^{1}$ Laboratory for Material and Joining Technology (LWF), Paderborn University, Paderborn, Germany \\ ${ }^{2}$ Institute of Manufacturing Technology (LFT), Friedrich-Alexander-Universität Erlangen-Nürnberg, Germany \\ Correspondence: Réjane Hörhold, Laboratory for Material and Joining Technology (LWF), Paderborn \\ University, Pohlweg 47-49, 33098 Paderborn, Germany. Tel: 0049-5251-60-5525. E-mail: hoerhold@lwf.upb.de
}

Received: May 23, 2017

doi:10.5539/jmsr.v6n4p19
Accepted: June 22, 2017

Online Published: August 9, 2017

\begin{abstract}
Economic conditions as well as comfort and safety-related requirements lead to lightweight design especially in automotive body-in-white production processes. The consequential multi-material mix limits the reliability of conventional thermal joining technologies. Innovative mechanical joining technologies need to be established. Following the lightweight-design requirements, next step for weight-reduction would be the renunciation of additional elements. Clinching technologies support this idea by creating a form- and force-fitting joint, but are limited to the formability of the joining partners. Joining by forming without additional elements even of hot formed ultra-high-strength manganese steels and ductile aluminium can be realised by shear-clinching. A precisely coordinated tool setup initialises a crack in the die-sided material with limited formability without harming the punch-sided ductile aluminium. This paper presents current and detailed investigations of the influences of mechanical loads on strength capacity of multi-material joints using shear-clinching technologies. The results clearly show the promising potential and challenges of this innovative single-step joining technology for multi-material mixes.
\end{abstract}

Keywords: Mechanical joining; clinching; multi-material mix; body-in-white; UHSS, joint strength

\section{Introduction}

Not only saving energy or resources during production process or reducing the carbon dioxide exhaustion when being in use lead to multi-material mixes in car body-structures. A ductile car body has to transform crash energy into forming energy in a frontal crash. The same car body has to be high rigid to avoid any deformation of pillars or other components reaching inside the cabin in a side impact. With regard to an efficient interaction of decreasing resources and suitably tailored materials with different added alloy elements and the implementation of high developed modern materials, innovative joining technologies are required. The efficiency of resistant spot welding is no longer a unique selling point for automotive joining technologies when joining e.g. aluminium and steel. Caused by the reduced solubility of $\mathrm{Fe}$ in $\mathrm{Al}$ at room temperature and the formation of brittle intermetallic phases, the focus now is on mechanical joining technologies. Main advantage are the absent of thermal harm of the material and an immediate mechanical strength. To achieve a form- and force-fitting joint, a mandatorily minimum formability is required (Mori et al., 2013). Current technologies manage to join multi-material mixes with one brittle joining partner by arranging it where no formability is necessary or by pre-holing it. Mechanical clinching joins multi-material mixes even of ultra-high-strength steel (UHSS) in multi-stage processes without additional joining elements. Shear-clinching technologies can realise a round-point joint of UHSS in a single-stage process (Busse et al., 2010). For a reliable and predictable process, the robustness has to be proven under laboratory conditions regarding several influencing factors.

\subsection{Challenges for Mechanical Clinching Technologies}

Mechanical clinching is described in DIN 8593 as a state of the art joining by plastic deformation technology for electric devices, coated components and body-in-white processes. The absence of additional joining elements increases the robustness of the process by neglecting quality systems for joining elements and feeding units (Varis, 2006). In order to join brittle material, a cutting operation is needed to guarantee the subsequent forming of a positive joint by the ductile material. State of the art is a pre-hole operation for symmetrical round clinches and an 
integrated cutting step for rectangular clinches. Integrated cutting operations offer the advantageous robustness of a single-stage process, without retrieval of a pre-hole (Hahn \& Klemens, 1996). To reach a symmetrical load-capacity round-point clinches are preferred (DVS/EFB-3420, 2012). These joints were firstly mentioned by (Thies, 1897). Figure 1 offers a view inside the processes. The toolset consists of punch, blankholder and die - in this case with opening lamellae. The blankholder fixes and preloads the sheet metals. The punch draws both materials into the die until they are reaching the die ground. A radial flow of the material is enabled by the opening lamellae and generates a form- and force-fitting joint, realised by an interlock. The tool geometry determines the joint formation (De Paula et al., 2006). Unfortunately, joining by forming is restricted by the formability and the strength of the materials (DVS/EFB3420, 2012). Similarly was stated in (Abe et al., 2008), but mainly referred to the tensile strength. Quality and strength of mechanical clinched joints are defined by the material properties of the joining partners (Lee, 2010). How to control the joining process of die-sided UHSS with tensile strength at 980 MPa and ductile aluminium by using adapted die-sided toolsets is documented in (Abe et al., 2012). Special solutions for symmetrical round-points were developed to join UHSS with more than $1000 \mathrm{MPa}$. State of the art is clinching with pre-hole on die-side for multi-material mixes in combination with UHSS. In case of pre-punching, the authors show, that a large interlock is supported by using a certain cutting clearance between punch and die (Müller et al., 2014). After retrieving the pre-hole in a multi-stage process, the procedural steps are comparable to the conventional round-point clinching process. An innovative technology is single-stage shear-clinching, developed by (Busse et al., 2011, Weikelmann, 2015).

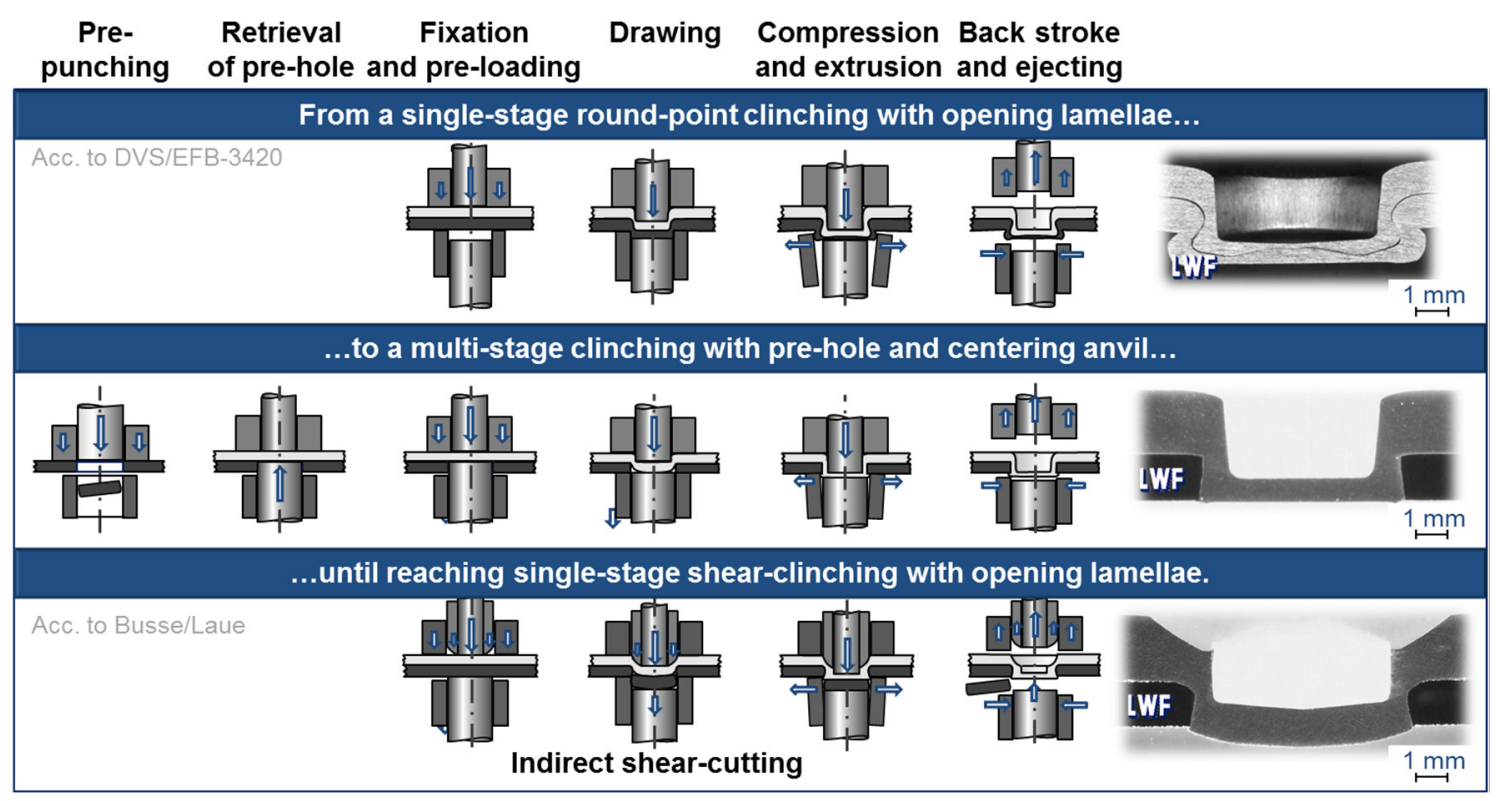

Figure 1. Evolution of round-point clinching technologies

\subsection{Joining of Aluminium and UHSS by Shear-Clinching}

Shear-clinching combines shear-cutting and the formation of a form- and forcefitting joint, detailed pictured in Figure 2. It offers the possibility to join die-sided UHSS without previous process-steps like pre-holing and the retrieval this. The two-parted punch includes a directly driven inner and a spring-loaded outer punch. The die-sided tool is comparable to the clinching with pre-hole tool with the prior to act as a cutting die. The sphere-like punch set initializes a separation of the die-sided slug without harming the punch-sided material. The impression of the outer punch creates the characteristic upper neck thickness tun and controls the material flow of the punch-sided material. The inner punch draws the ductile joining partner to create a form- and force-fitting joint, defined by residual bottom thickness tb and lower neck thickness th, interlock $\mathrm{f}$ and element height $\mathrm{h}$. After separation the slug remains on top of the anvil. 


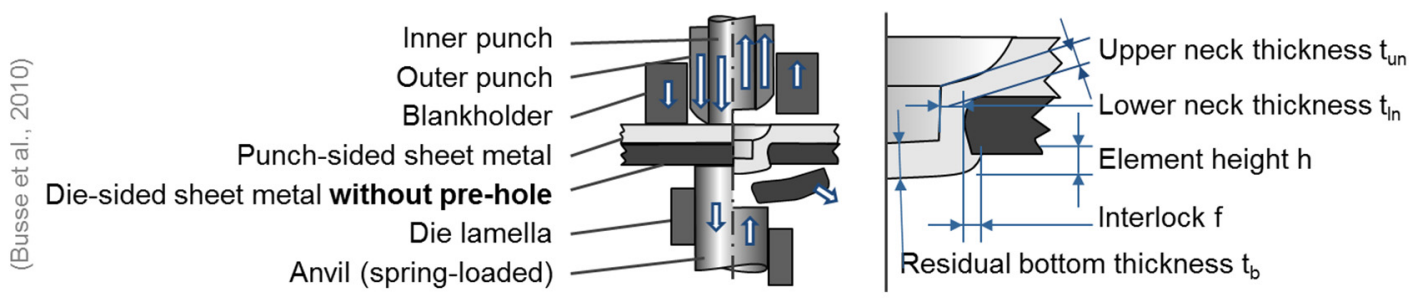

Figure 2. Sequence and characteristics of single-stage shear-clinching (Busse et al., 2010)

\subsection{Joining by Forming: Influence of Specimen's Geometry on Joint Formation}

(Mucha, 2011) describes, that the joint rigidity and load capacity of a conventional joined double-hat clinching elements depends on the loading method. Additionally, he mentioned a load bearing cross-section consisting of the neck thickness $t_{n}$, the interlock $f$ and the joint diameter. A divergent material distribution therefore highly influences this cross-section formation and in that conclusion the load capacity.

The form- and forcefitting shear-clinched joint is mainly created by compressing and extruding the punch-sided material into the punched hole of the die-sided material. While joining quasistatic specimens the effect occurs, that a smaller edge distance influence the cross-section formation. The punch-sided material uses the line of least resistance by flowing outside the joining zone. This paper depicts the characteristics of joining and testing different geometries to describe this effect. Additionally, the level of the joining force depends on the cutting force needed to separate the die-sided material. To analyse the impact of the joining force, two different die-sided materials were used. The significant influence of the friction coefficient between both sheets have been analysed in (Weikelmann, 2016a).

\section{Method}

In (Hörhold et al., 2016) the good performance of shear clinched joints compared to state of the art process clinching with pre-hole is described. Main topic of this paper is the joint formation and load capacity of shear-clinched specimens with regard of the specimen's rigidity due to geometry and joining material.

\subsection{Materials and Specimens}

Figure 3 depicts the characteristics of the chosen tool setup and the properties of the joining partners. Following (Lambiase, 2013), the fixed anvil reduces the material flow in joining direction (die depth $2.0 \mathrm{~mm}$ ). The opening lamellae (diameter $7.0 \mathrm{~mm}$ ) enable a lateral extrusion of the punch-sided material and the holding of the die-sided slug. The inner punch has a diameter of $5.6 \mathrm{~mm}$, the characteristic outer punch radius is $6.0 \mathrm{~mm}$ with a chamfer (circular ring area perpendicular to aluminium surface) of $0.3 \mathrm{~mm}$.

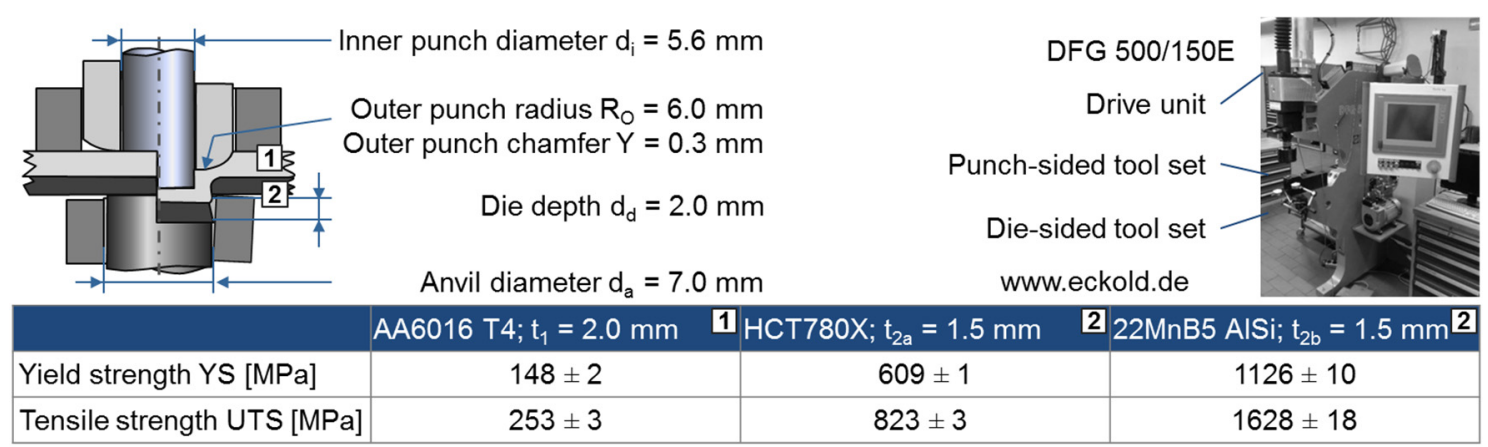

Figure 3. Experimental setup for the investigations in this paper

Both investigated material configurations were conducted with punch-sided ductile aluminium alloy AA6016 (AlSi1.2Mg0.4) in temper $\mathrm{T} 4$ and thickness of $\mathrm{t}_{1}=2.0 \mathrm{~mm}$. After solution heat treatment and naturally aging it reaches the temper T4 and additionally higher strength due to hardening by forming. Configuration a arranges a dual phase steel HCT780X (1.0943) with zinc-coating in $\mathrm{t}_{2 \mathrm{a}}=1.5 \mathrm{~mm}$ and $800 \mathrm{MPa}$ UTS on die-side. With same thickness configuration $b$ has a 22MnB5 (1.5528) on die-side with $1600 \mathrm{MPa}$ UTS due to martensite formation 
during quenching. The AlSi-coating on the steels' surface avoids scale formation during heat treatment (ArcelorMittal, 2014). First part of the investigations was the feasibility by sampling both configurations on a C-shaped stand machine DFG 500/150E with a maximum load of $150 \mathrm{kN}$ and a high-rigidity of appr. $65 \mathrm{kN}$. Sampling is performed on $45 \mathrm{~mm} \times 45 \mathrm{~mm}$ specimen with a concentrically positioned joining zone.

\subsection{Quasistatic Testing}

Joint strength tests of both material configurations are conducted on single-lap shear specimen for shear load $\left(0^{\circ}\right.$, suggested edge distance of $8 \mathrm{~mm})$ and on cross tension test specimen for tensile load $\left(90^{\circ}\right.$, geometry related edge distance of $25 \mathrm{~mm}$ ). All specimen's characteristics are pictured in detail in Figure 4 and (DVS/EFB-3480, 2007). The quasistatic tests were performed on high-rigid universal testing machines (ZWICK Z100) at same testing velocity of $10 \mathrm{~mm} / \mathrm{min}$. End of testing is the complete separation of the joint, displacement and forces were measured to analyse the damage behaviour. The damage behaviour of the joints is determined according to DIN EN ISO 12996. Depending on the load direction, main modes of failure are neck fracture and unbutton (Lee et al., 2010).

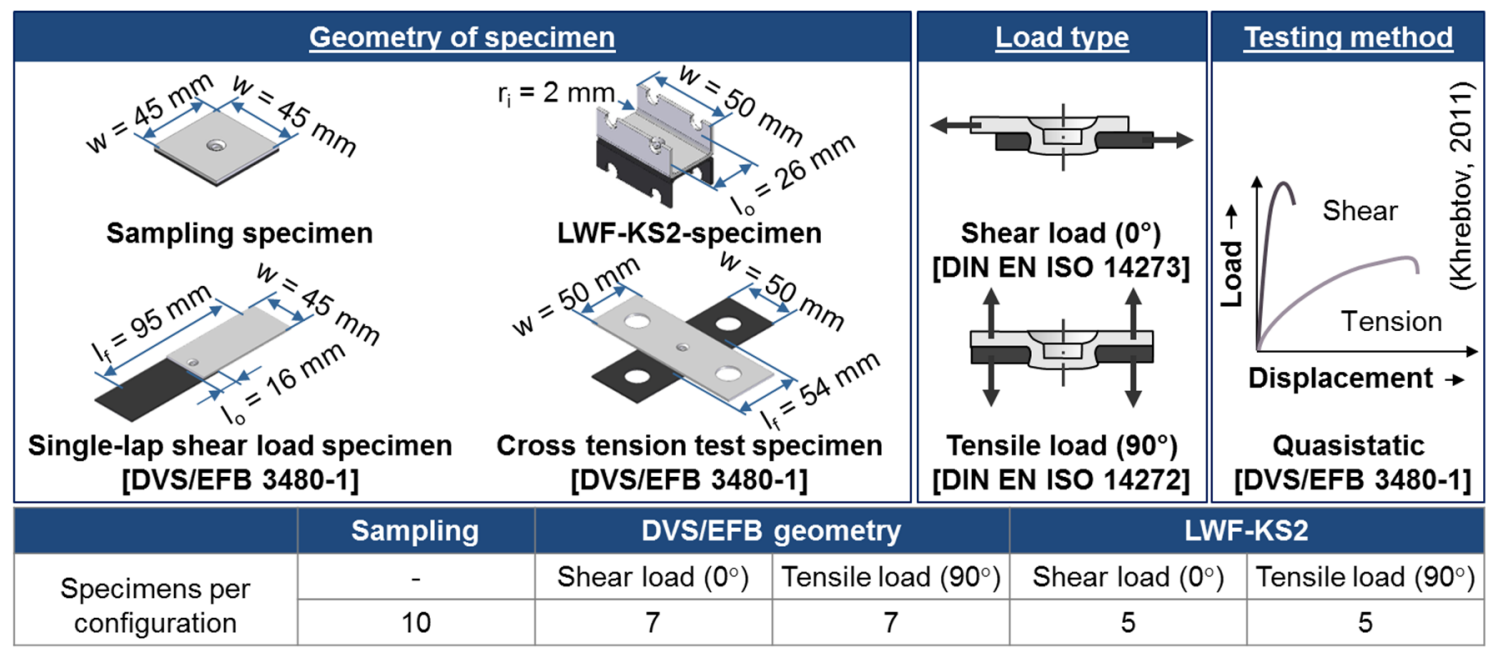

Figure 4. Geometry of specimens and testing method investigated in this paper

\section{Results}

\subsection{Joining UHSS by Shear-Clinching}

\subsubsection{Sampling}

First, a fitting tool setup for both material configurations is defined. Criterions for a successful sampling are the full slug-release during the joining process and no cracks in the aluminium. For both configurations, the residual bottom thickness in the middle of the joint achieves about half the thickness of the origin aluminum sheet metal thickness. For HCT780X on die-side the minimum $t_{\mathrm{b}}$ is $0.96 \mathrm{~mm}$, whereas the spheric bulge of the button in the $22 \mathrm{MnB} 5$ causes a minimum $\mathrm{t}_{\mathrm{b}}$ of $0.66 \mathrm{~mm}$ in the edge region. After releasing a slug, the higher strength material is not formable enough to get flattened, therefore the button remains spheric, despite of an almost even material distribution of the aluminium in the HCT780X onset. The resistance against forming the slug of the 22MnB5 causes higher counter pressure, therefore $t_{u n}$ as a measurable value of impressing the outer punch inside the punch-sided material, remains smaller. In Figure 5, next to the cross-sections of the two material configurations the measured geometric characteristics compared to Figure 2 can be found. Another die-sided material related effect occurs, when regarding the interlock formation. Despite of a similar fracture angle in die die-sided material, the measured interlock with a die-sided HCT780X is significantly higher. The less the UTS of the die-sided joining partner the significantly higher is the interlock $\mathrm{f}_{\mathrm{HCT}}=0.36 \mathrm{~mm}$ and $\mathrm{f}_{22 \mathrm{MnB} 5}=0.12 \mathrm{~mm}$ ). With a regard on the geometric characteristics of configuration a, due to a better radial aluminium material flow on die-side, a higher interlock is created despite of a larger residual bottom thickness. Caused by the same tool set, the inner punch creates in both cases a comparable tln of $0.52 \mathrm{~mm}$ whereas the die depth creates an element height of $\mathrm{h}_{\mathrm{HCT}}=0.86 \mathrm{~mm}$ and $\mathrm{h}_{22 \mathrm{MnB} 5}=0.93 \mathrm{~mm}$. It was observed, that the blankholder fixation can not prevent combination $b$ from pushing itself out of the die. Another significant effect occurs when analysing the cutting 
behaviour of the die-sided material. The roll over as a transistion between surface and fracture zone is wider for the HCT780X. This could prevent harm of the punch-sided material. Summarised, the joint formation depends on the die-sided material, from that both configurations are feasible.
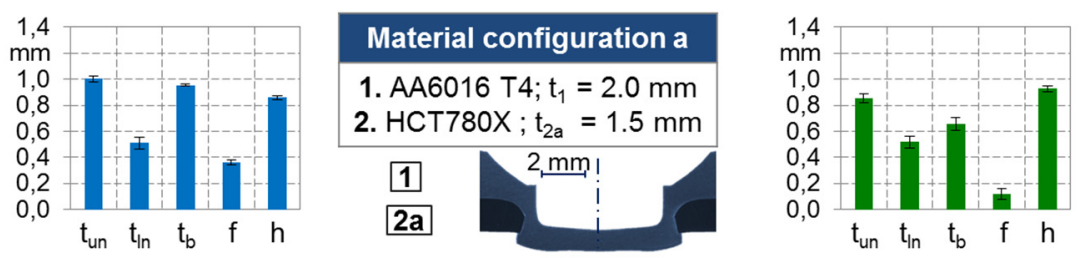

Material configuration b

1. $A A 6016 T 4 ; t_{1}=2.0 \mathrm{~mm}$

2. $22 \mathrm{MnB} 5 ; \mathrm{t}_{2 b}=1.5 \mathrm{~mm}$

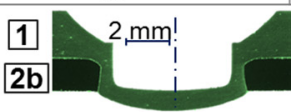

Figure 5. Geometric characteristics and cross-sections of both material configurations

\subsubsection{Insights Inside the Process via Online-Monitoring}

The adapted process monitoring enables a detailed view at all stages of the shear-clinching process with a very high measurement rate. In Figure 6, the curves show the same two characteristic peaks. The first peak describes the required cutting force to separate a slug from the die-sided material. The second, maximum peak shows the needed joining force to get a form- and force-fitting joint by radial extrusion of the aluminium joining partner. The bar charts added left to each curve separated the forces into their cutting and forming part related to specimen's geometry. The average cutting force $\mathrm{F}_{\mathrm{C}}$ for separating HCT780X during the shear-clinching process was $47 \mathrm{kN}$. The hot formed 22MnB5 was separated at $60 \mathrm{kN}$ and showed an explicit cutting impact. Regarding the maximum forces between both configurations, the HCT780X needed marginally less force to achieve a good joint formation. Besides, the comparison of the joint formation between experiment and developed FEM-model the authors show in (Merklein et al., 2014; Müller et al., 2015) matches both configurations very well and shows a higher stress inside the button of the $22 \mathrm{MnB} 5$ due to resistance against flattening the slug.
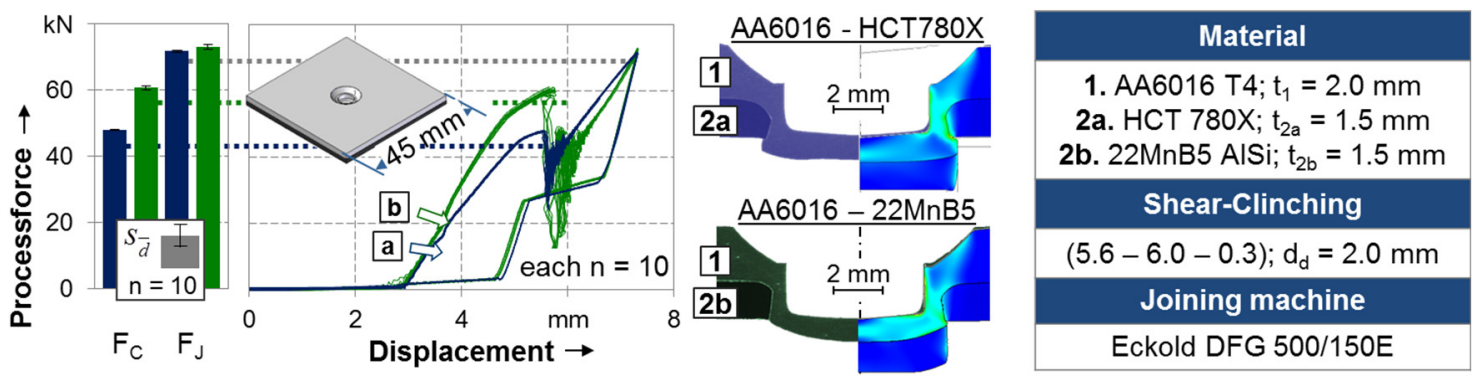

Figure 6. Online-monitoring of sampling both material configurations

Regarding separately the joining forces of only one material configuration related to the joined specimen's geometry, a significant effect appears (see Figure 7). A difference between the maximum joining forces depending on the specimen's geometry occurs. In both configurations, a clear decline of the maximum joining forces can be found, when joining single lap shear load specimens instead of cross tension test specimens. Although the cutting forces for both geometries remains the same concerning each configuration, a detailed glance at cutting force level offers a small deviation in displacement. The cutting force for shear specimen is reached at a larger displacement.

The explanation is given by the edge distance of both geometries (Figure 8). The single lap shear specimen has a minimal edge distance of $8 \mathrm{~mm}$. This small edge distance offers the possibility to press aluminium out of the joining zone. This material is being missed, when creating a joint with a certain bottom thickness, so less force is needed to form the joint. Almost the opposite shows the cross tension test specimen where a square of 50 times $50 \mathrm{~mm}$ disables a radial material distribution out of the joining zone. The aluminium has to be pressed into the hole in the die-sided material and into the die, so more force is needed in total. The higher the cutting force, the higher is the difference between both geometries. In summary it can be said, that the specimen's geometry, especially the 
edge distances, affects the joint formation significantly. For self-piercing riveting (SPR), (Li et al., 2012) already shown the significance of the edge distance.
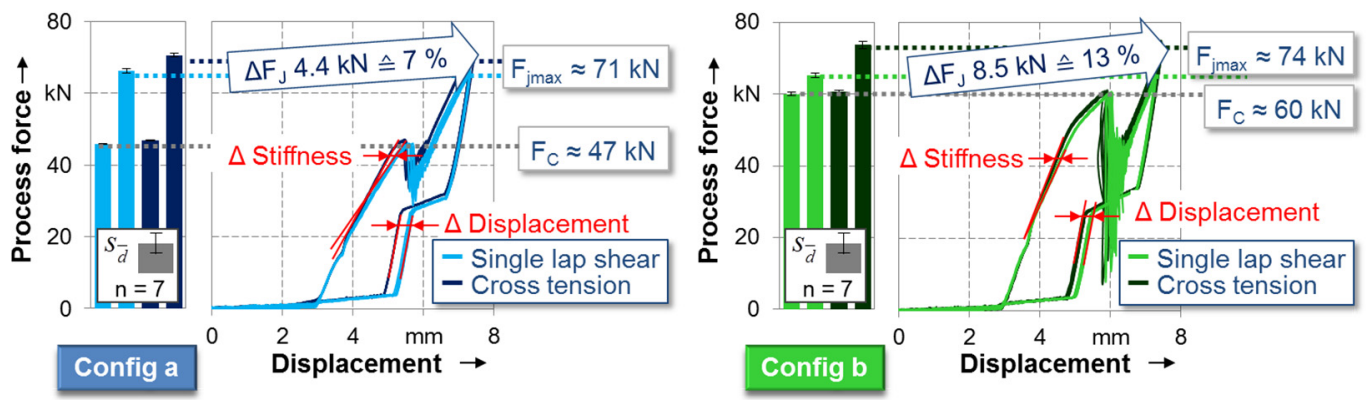

Figure 7. Online-monitoring of joining both material configurations/specimen's geometries

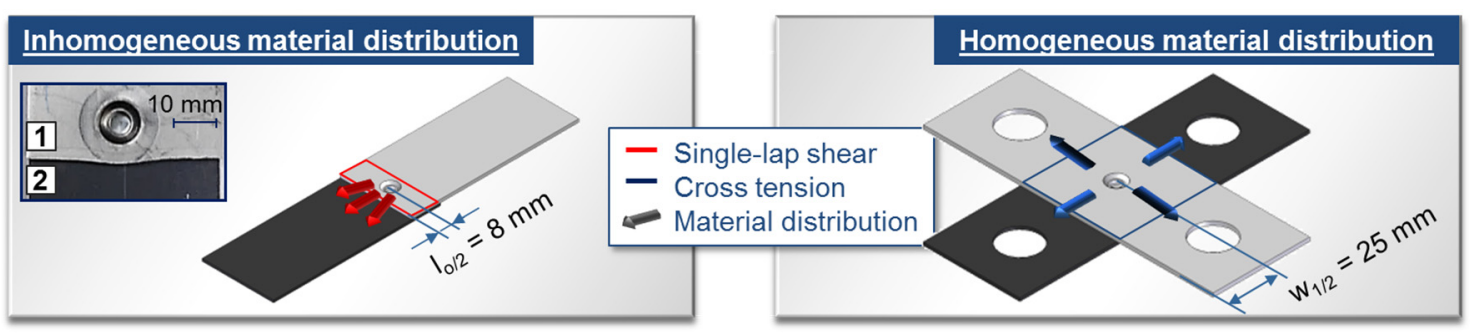

Figure 8. Principle of material distribution during the joining process

\subsection{Load-Bearing Capacity of Shear-Clinched Joints}

\subsubsection{Influence of material configuration and load direction on load capacity}

This chapter depicts the results of quasistatic testing the two configurations under shear load using single-lap shear load specimens and tensile load using cross tension test specimens. In all configurations and load directions seven samples were tested. Figure 9 shows the force-displacement-curves of all tests conducted on these specimens including a bar chart with the maximum forces occurring during testing. Both configurations show reproducible damage behaviour by neck fracture. The tests have only small deviations and comparable curves as mentioned in (Khrebtov, 2011). In shear strength, they reach about $3 \mathrm{kN}$, with a slightly better performance of configuration $b$. Regarding the single lap shear load specimen, the immense material flow out of the joining zone when joining can be detected by regarding the material distribution of the punch-sided aluminium out of the joining zone. In tensile strength, the small interlock only offers small tensile strength. But $2 \mathrm{kN}$ in average are more than the typically minimal required handling strength (appr. $0.5 \mathrm{kN}$ ). At same force level, the die-sided dual phase steel reaches a path of $5 \mathrm{~mm}$ in average. The hot formed steel is damaged after $4 \mathrm{~mm}$.

\subsubsection{Influence of Specimen's Geometry on Damage Characteristics}

Regarding the cross tension test specimens as shown above, the immense deformation of the ductile joining partner distorts the results. Summarised, a significant influence of the specimen's geometry can be detected by process monitoring as well as during quasistatic tests. To reduce the effect of the influence of the specimen's geometry on joint formation and test behaviour, LWF-KS2-specimens were used to perform the next test program. This causes due to one specimen's geometry and stiffness the same joining forces for both load directions.

Compared to the conventional test specimens, some new effects occur (Figure 10). The stiffness of the shear loaded specimens seems lower, when testing KS2, due to the traverse path detection. Single-lap-shear loaded specimens were measured by local path displacement (FDM). Due to an equally loaded ring surface of the aluminium in the neck area, the tensile loaded specimens bear more displacement. The difference between both stiffnesses is remarkable due to path measurement for both specimens rely on traverse movement. The cross tension test specimen enables a large displacement and deformation of the joint. As a result, the joining element fails earlier compared to the LWF-KS2-specimen. 

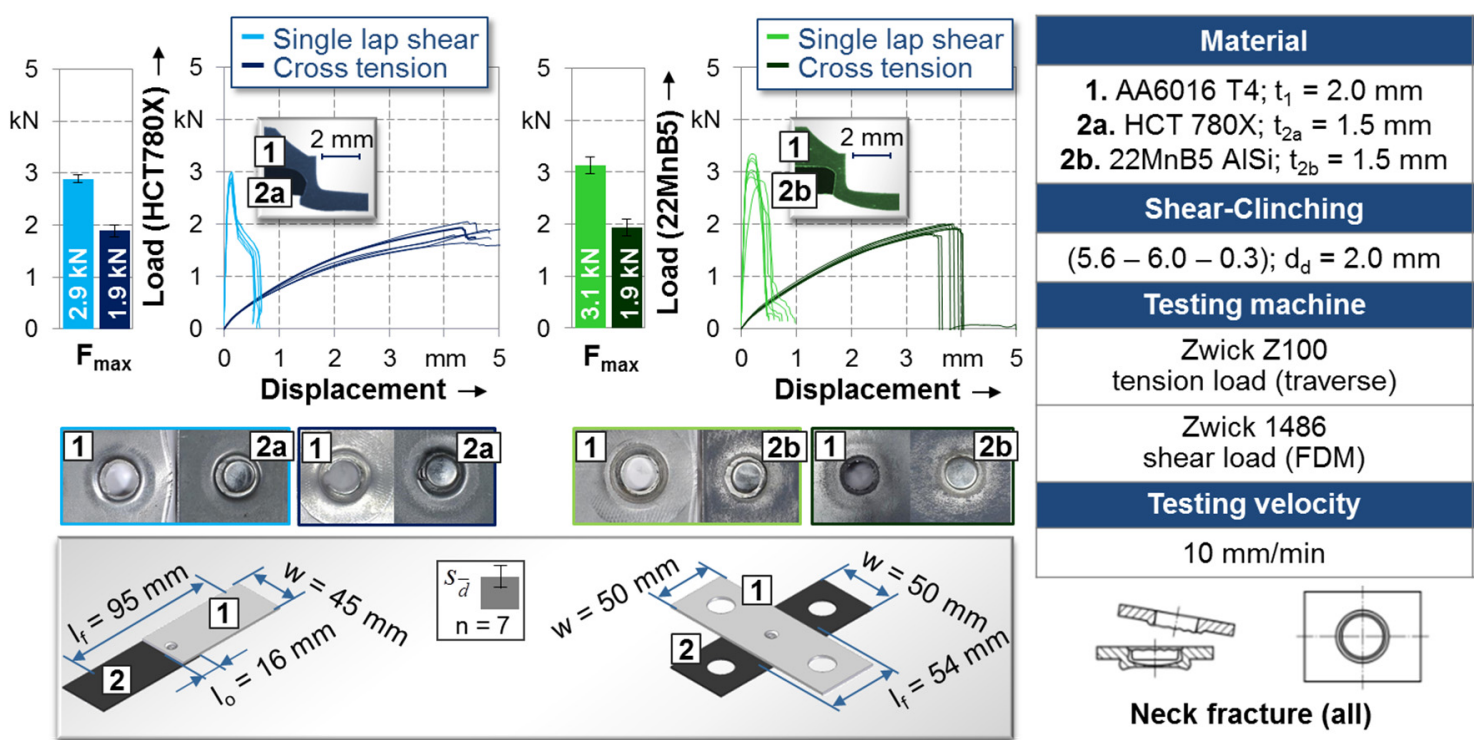

Figure 9. Quasistatic joint strength of investigated conventional specimens
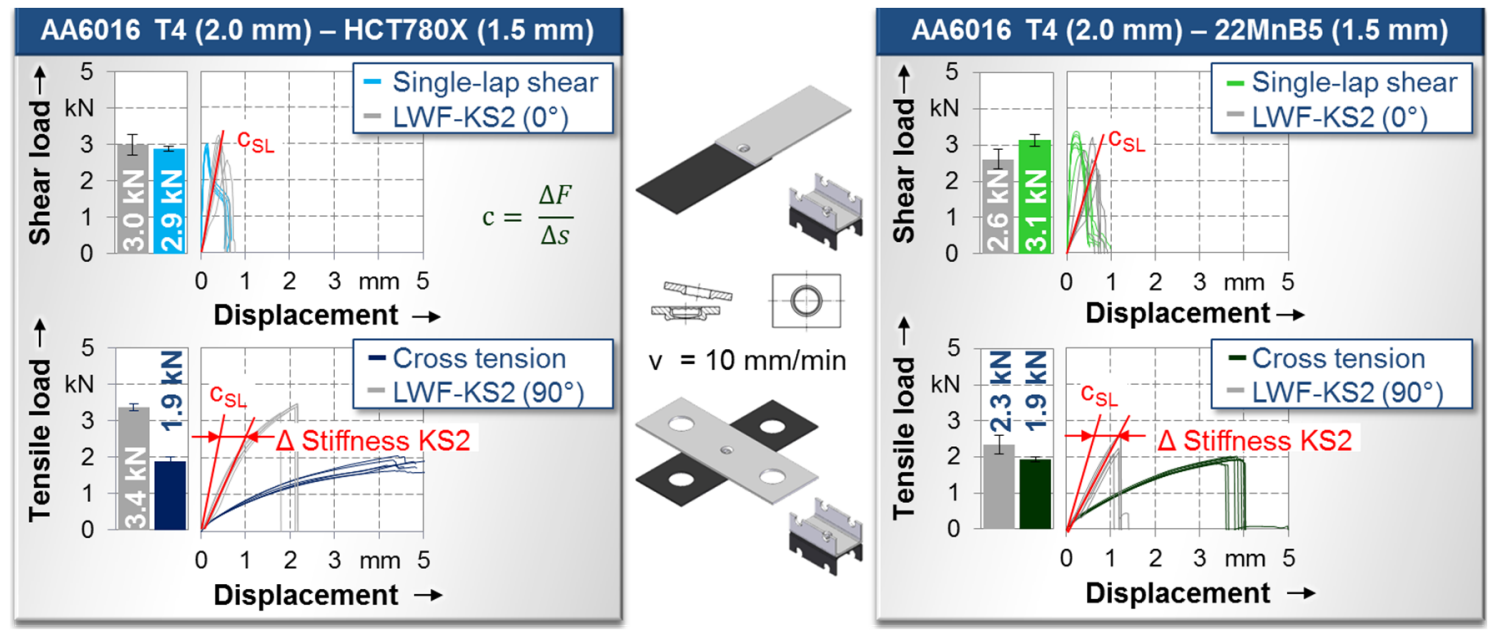

Figure 10. Comparison of quasistatic joint strength of investigated specimens

\section{Discussion and Conclusion}

\subsection{Joining UHSS by Shear-Clinching}

Shear-clinching can join dissimilar materials, even hot formed UHSS without additional joining elements, thermal influences or pre-holes - only by plastic deformation. This paper offers results of a reproducible shear-clinching process for two different UHSS (multiplication factor of 2 regarding the UTS) on die-side with the same tool setup and machine settings. The adapted process-monitoring can detect influences of the die-sided material and the edge distance on joint formation. Due to the interlock formation only by joining by forming, high joining forces are required. Therefore, the material flow depends on the edge distance, as a lower edge distance causes a lower resistance against material flow outside of the joining zone. Especially the developed FEM-model the authors show in (Merklein et al., 2014; Müller et al., 2015) will support optimising the process.

\subsection{Load-Bearing Capacity of Shear-Clinched Joints}

In quasistatic joint strength tests, shear-clinching reaches good and reproducible values for quasistatic joint strength. To realise a reproducible and predictable process, the fundamental characterisation of guidelines for minimum edge distances and specimen's geometries and tool design adaptions for a better material flow control are mandatory. Standard test specimens shall be used for shear or tensile tests, especially regarding the smaller 
effort and availability of plane sheet metals. Regarding shear strength and specimens rigidity, the authors recommend a minimum edge distance of $9 \mathrm{~mm}$ when joining AA6016 (2.0 mm) and 22MnB5 (1.5 mm) (Figure 11). To compare different load directions, the same specimen's geometry has to be used, e.g. LWF-KS2, to avoid deviating joint formation due to different stiffness and edge distances and therefore different energy absorption and damage behaviour.
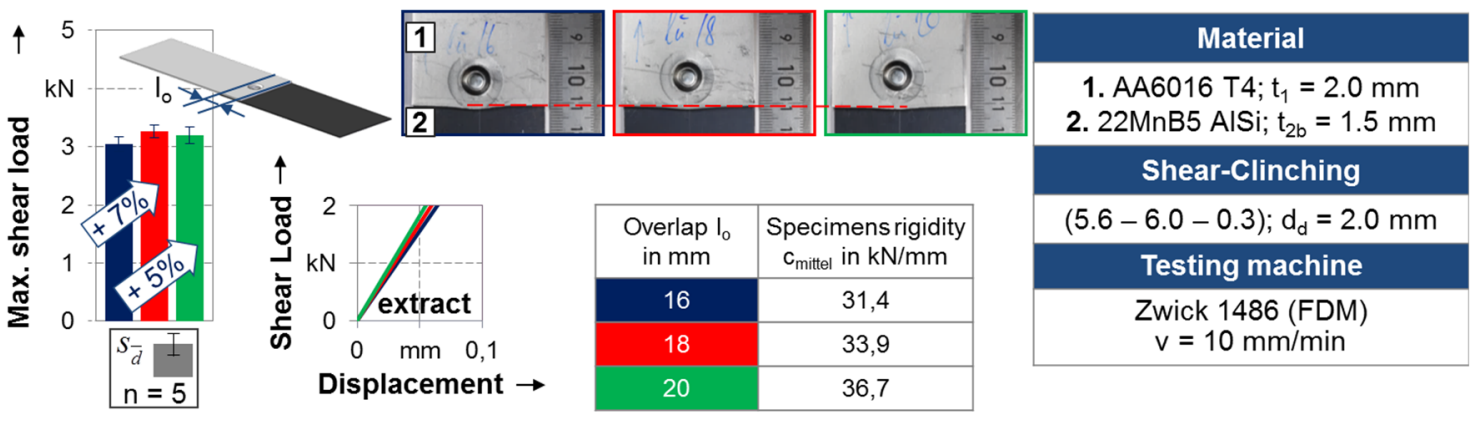

Figure 11. Recommended edge distance for single-lap shear load specimen

By now, multi-stage clinching with pre-hole on die-side remains state of the art joining technology when joining ductile material and UHSS. But shear-clinching offers great potential as an alternative joining technology for further critical joining tasks. Applications in multi-material design with a desired single-stage joining process and the absence of any additional joining element will benefit from this technology.

\section{Acknowledgments}

In this paper, selected results of the funded DFG research projects ME 1840/3-2 and ME 2043/37-2 were presented. The authors gratefully thank the German Research Foundation (DFG) for funding the research project ME 1840/3-2 and ME 2043/37-2 within the SPP 1640 with the title "Mechanical joining of dissimilar materials by shear-clinching processes without pre-punching (shear-clinching)".

\section{References}

Abe, Y., Matsuda, A., Kato, T., \& Mori, K. (2008). Plastic Joining of Aluminium Alloy and High Strength Steel Sheets by Mechanical Clinching, Steel Research International, Special Edition 79(1), pp. 649-657. DOI: https://doi.org/10.1080/09507110802410361

Abe, Y., Mori, K., \& Kato, T. (2012). Joining of high strength steel and aluminium alloy sheets by mechanical clinching with dies for control of metal flow, Journal of Materials Processing Technology, pp. 884-889. DOI: https://doi.org/10.1016/j.jmatprotec.2011.11.015

ArcelorMittal (2014). Steels for hot Stamping -Usibor ${ }^{\circledR}$ Automotive, Extract from the product catalogue European edition.

Busse, S., Merklein, M., \& Roll, K. (2010). Development of a Mechanical Joining Process for Automotive Body-In-White Production. International Journal of Material Forming 3, pp. 1059-1062. DOI: https://doi.org/10.1007/s12289-010-0953-3

Busse, S., Merklein, M., Roll, K., Zürn, M., \& Schubert, H. (2011). Numerical and Experimental Investigations of an Innovative Clinching Process, Proceedings of the 10th International Conference on Technology of Plasticity (ICTP), Düsseldorf, pp. 736-741.

ISBN: 978-3-514-00784-0

De Paula, A., Aguilar, M., Pertence, A., \& Cetlin, P. (2006). Finite element simulation of the clinch joining of metallic sheets. Journal of Material Processing Technology 182, pp. 352-357.

DOI: https://doi.org/10.1016/j.jmatprotec.2006.08.014

DIN EN ISO 12996. (2013). Mechanical joining - Destructive testing of joints - Specimen dimensions and test procedure for tensile shear testing of single joints

German version EN ISO 12996:2013

DVS/EFB-Merkblatt 3420. (2012). Mechanical Clinching - Overview (in German). 
DVS/EFB 3480-1. (2007). Testing of joint properties (in German).

Hahn, O., \& Klemens, U. (1996). Joining by Forming Riveting and Clinch Joints — Innovative Joining Procedures for the Practice, Documentation 707 (in German).

Hörhold, R., Müller, M., Merklein, M., \& Meschut, G. (2016). Mechanical properties of an innovative shear-clinching technology for ultra-high-strength steel and aluminium in lightweight car body structures, Welding in the World, Vol. 60, Issue 3, pp. 613-620

DOI: https://doi.org/10.1007/s40194-016-0313-0

Khrebtov, P. (2011). Neuartiges Verfahren zur Online-Prozessüberwachung und -Fehlerklassifizierung beim Durchsetzfügeverbinden von Blechen, Dissertation, Technischen Universität Clausthal urn:nbn:de:gbv:104-1105917

Lambiase, F. (2013). Influence of process parameters in mechanical clinching with extensible dies, International Journal of Advamced Manufacturing Technology 66, pp. 2123-2131

DOI: https://doi.org/10.1007/s00170-012-4486-4

Lee, C.-J., Kim, J.-Y., Lee, S.-K., Ko, D.-C., \& Kim, B.-M. (2010). Parametric study on mechanical clinching process for joining aluminum alloy and high-strength steel sheets, Journal of Mechanical Science and Technology 24, pp. 123-126. https://doi.org/10.1007/s12206-009-1118-5

Li, D., Han, L., Thornton, M., \& Shergold, M. (2012): Influence of edge distance on quality and static behaviour of self-piercing riveted aluminium joints, Materials \& Design, Volume 34, pp. 22-31. https://doi.org/10. 1016/j.matdes.2011.07.046

Merklein, M., Meschut, G., Mueller, M., \& Hoerhold, R. (2014). Basic investigations of non-pre-punched joining by forming of aluminium alloy and high strength steel with shear-clinching technology, Key Engineering Materials Vols. 611-612, pp. 1413-1420. https://doi.org/10.4028/www.scientific.net/KEM.611-612.1413

Mori, K., Bay, N., Fratini, L., Micari, F., \& Tekkaya, A. E. (2013): Joining by plastic deformation, CIRP Annals Manufacturing Technology, Volume 62, Issue 2, pp. 673-694. https://doi.org/10.1016/j.cirp.2013.05.004

Mucha, J. (2011). The analysis of lock forming mechanism in the clinching joint, Materials and Design 32 (10), pp. 4943-4954. https://doi.org/10.1016/j.matdes.2011.05.045

Müller, M., Hörhold, R., Merklein, M., \& Meschut, G. (2014). Analysis of material behaviour in experimental and simulative setup of joining by forming of aluminium alloy and high strength steel with shear-clinching technology, Adv. Mater. Res. 966-967, pp. 549-556. https://doi.org/10.4028/www.scientific.net/AMR.966 $-967.549$

Müller, M., Hörhold, R., Meschut, G., \& Merklein, M. (2015). FE-based study on the cutting operation within joining by forming dissimilar materials using shear-clinching technology, Applied Mechanics and Materials, Vol. 794, pp. 304-311. https://doi.org/10.4028/www.scientific.net/AMM.794.304

Thies, L. (1897). Joining of sheet metal, German Reichspatent DRP-Nr. 98517 (in German).

Varis, J. (2006). Economics of clinched joint compared to riveted joint and example of applying calculations to a volume product, Journal of Materials Processing Technology, 130-138. https://doi.org/10.1016/j.jmatprotec. 2005.09.009

Weikelmann, A., Schubert, H., \& Meschut, G. (2015): Influences of adhesives on the shear clinching technology for joining ultra high-strength steel and alumum, proceedings of Aluminium - Building the Future, GDA

Weikelmann, A., Schubert, H., \& Meschut. G. (2016a): Reibwert beim Schneidclinchen untersucht (Shear clinching: Influence of friction coefficient), UMFORMtechnik 02, pp. 18-20

Weikelmann, A., Schubert, H., \& Meschut, G. (2016b): Shear clinching technology for joining ultra-high-strength steel and aluminum, proceedings Joining In Car Body Engineering, Automotive Circle

\section{Copyrights}

Copyright for this article is retained by the author(s), with first publication rights granted to the journal.

This is an open-access article distributed under the terms and conditions of the Creative Commons Attribution license (http://creativecommons.org/licenses/by/4.0/). 